Research Article

\title{
Mechanical Performance Analysis and Parametric Study of a Self-Anchored Suspension Bridge with Ultra-Wide Double-Sided Steel Box Girder
}

\author{
Fangwen $W u\left(\mathbb{D},{ }^{1}\right.$ Wenlong Tang $\left(\mathbb{D}\right.$, , Shuo Liu $\mathbb{D}^{1},{ }^{1}$ Yanpeng Feng $\mathbb{D}^{1},{ }^{1}$ \\ Guangqian Wang $\mathbb{D}^{1}$, and Maohua Du $\mathbb{D}^{2}$ \\ ${ }^{1}$ School of Highway, Chang'an University, Xi'an 710064, China \\ ${ }^{2}$ Naval University of Engineering, 717 Jiefang Road, Qiaokou District, Wuhan 430033, China \\ Correspondence should be addressed to Maohua Du; 18207157778@139.com
}

Received 3 January 2021; Accepted 25 May 2021; Published 7 June 2021

Academic Editor: Tayfun Dede

Copyright (C) 2021 Fangwen Wu et al. This is an open access article distributed under the Creative Commons Attribution License, which permits unrestricted use, distribution, and reproduction in any medium, provided the original work is properly cited.

\begin{abstract}
A sufficient understanding of mechanical performance of self-anchored suspension bridge with double-sided steel box girder is essential for design and normal use as such bridges are widely built in urban bridge. Using the Yunlongwan Bridge which is a suspension bridge with ultra-wide double-sided steel box girder as an example, this paper investigates its deformation and mechanical performance under vehicle load. Firstly, based on the field test results, the deformation performance of the bridge and the stress distribution of the main girder are analysed, with emphasis on the shear lag effect of double-sided steel box girder. Then, a multiscale model of the bridge was built, and the accuracy of the model was verified by comparison with the test data. Finally, the influence of design parameters on the mechanical behaviour of double-sided steel box girder is studied by numerical simulation. The results show that the deformation of the bridge has good symmetry, there is obvious shear lag effect on the main girder, and the U-rib thickness, diaphragm spacing, and vehicle load could significantly affect the stress of the main girder top plate. The obtained analytical results lead to a better understanding of the mechanical performance and provide reference for the design of self-anchored suspension bridge with double-sided steel box girder.
\end{abstract}

\section{Introduction}

Due to the progress of bridge construction technology and the demand for practicability and appreciation of municipal bridges, self-anchored suspension bridge has become a very competitive bridge type because of its economy, elegant appearance, good adaptability, and reasonable stress state [1]. At the same time, with the continuous growth of the requirement for bridge traffic capacity, the widths of bridges develop to eight lanes or even wider, which makes the proportion of structural self-weight in structural design rising gradually [2]. To reduce the dead weight of the beam as much as possible, the thin-walled steel box girder is generally used as the stiffening girder of bridge [3]. Doublesided steel box girder is a special form of thin-walled steel box girder which is developed through the application of practical engineering. It reduces the self-weight and widens the bridge by removing the bottom plate of steel box girder, and adds a diaphragm or crossbeam to ensure the integrity and torsional stiffness [4]. Hence, some self-anchored suspension bridges with double-sided steel box girder have been applied to practice. These bridges with large span and width play important roles as traffic hubs in the actual use and have been in a heavy traffic environment, which makes their deformation and mechanical behaviour more complex. These make the stress characteristics, stress distribution, and structural load response of self-anchored suspension bridge with double-sided steel box girder become key issues in the field of bridge engineering [5].

Vehicle load is the most common external load on bridge, and it is also one of the main causes of bridge damage [6]. In recent years, the increase in traffic volume and heavy 
vehicles leads the vehicle load to improve, which makes damage risk of the bridges caused by vehicle load increasing $[7,8]$. Therefore, it is necessary to study the mechanical properties of the bridge under vehicle load to understand the real deformation and stress state of the bridge, which is important to ensure safety and guide bridge design [9]. At present, researchers mainly study the influences of vehicle load on bridges through field tests, lab experiments, and numerical simulation [10]. Madrazo-Aguirre et al. [11] pointed out that it is dangerous for bridges to be subjected to eccentric loads, and the thickness of top plate and the type of beam section are the main factors that affect the load response of bridges. Cheng and Shen [12] found that the midspan deflection and suspender cable force gradually increased with the load, and due to the influence of random factors such as temperature and wind load, the bridge response would be random. Ding et al. [13] concluded that there is a time delay effect in the displacement of the main span of the bridge under the vehicle load, and the load would cause the deflection and the displacement vibration effect. Thus, the research studies on cable-stayed bridge, groundanchored concrete suspension bridge, and continuous beam bridge are relatively common, while few researchers have studied the deformation behaviour and load response of selfanchored suspension bridge under the action of vehicle load $[14,15]$.

In addition to the structural load response of the selfanchored suspension bridge, the mechanical behaviour of the main girder is also related to the safety the bridge. When the double-sided steel box girder is used as the main girder of the self-anchored suspension bridge, its spatial mechanical performance is complex under the influence of huge force and big width [16]. Zhou et al. [17] studied the stress distribution of double-sided box girder through field test, finding that under symmetrical load, the longitudinal stresses of beam top and bottom plate are M-shaped along the transverse direction, and the maximum stress increment is located at the junction of top, bottom plate, and inner web. Many studies show that there is an obvious shear lag effect in thin-walled box girders, which enhances beam width, and diaphragms and stiffening ribs would also affect it $[3,18]$. For double-sided steel box girders, the shear lag effect might be more prominent and even cause excessive local stress, resulting in structural damage. In sum up, the differences between this type of girders and common box girders are shown in Table 1. Therefore, it is necessary to research the shear lag effect of double-sided steel box girder. The section parameters design has a great influence on the stress distribution. Zang [19] studied the failure types and causes of bridge deck pavement and found that improper selection of design parameters and serious overloading were the two main reasons leading to the bridge deck pavement cracking. However, there is still a lack of research on the parameter design of double-sided steel box girder, and the influence of each structural size on the beam is not fully understood.

So as to make up for the deficiency of the existing research, in this paper, the Yunlongwan Bridge was used to study the overall mechanical properties and deformation of ultra-wide double-sided steel box girder self-anchored suspension bridge under vehicle load. The distribution of longitudinal stress and shear lag effect of main girder was emphatically analysed. Then, the multiscale model of the bridge was established using the finite element software ANSYS, and the accuracy of the model was verified by comparing the test data. Finally, based on the established model, the effects of U-rib thickness, diaphragm spacing, and vehicle load on the mechanical properties of the top plate of key sections were studied. This study contributes to the interpretation of the complex mechanical behaviour of self-anchored suspension bridges, which is of great importance for bridge design and operational safety.

\section{Example Bridge and Experimental Programme}

2.1. Basic Information of the Example Bridge. The Yunlongwan Bridge is a two-tower three-span self-anchored suspension bridge with double-cable face and ultra-wide double-sided steel box girder which has been completed, as shown in Figure 1. It is the largest self-anchored suspension bridge with the largest span and width in Sichuan Province. There are eight motorways, two nonmotorized vehicle lanes, and two footpaths on the deck.

The bridge span arrangements are $(30+80+205+80+30)$ $\mathrm{m}$, and the theoretical span of main bridge is $(83.2+205+83.2)$ $\mathrm{m}$. The main cables with double-cable surface adopt highstrength zinc-aluminum alloy parallel wire with an area of $0.0542 \mathrm{~m}^{2}$, and the distance between the two cables is $40 \mathrm{~m}$. There are 31 pairs of suspenders on the bridge, which are made of the same material as the main cable, and the cross-sectional area of each suspender is $0.004887 \mathrm{~m}^{2}$. The longitudinal distance between the two suspenders is $10 \mathrm{~m}$ in standard segments, and that between suspender and main tower is $13.5 \mathrm{~m}$. The main towers both are portal reinforced concrete bridge towers made of C40 concrete. The tower on the north bank is $61.25 \mathrm{~m}$ high, and that on the south bank is $59.55 \mathrm{~m}$. The elevation view of this bridge is shown in Figure 2.

\subsection{Configuration of the Ultra-Wide Double-Sided Steel Box} Girder. The main girder of the Yunlongwan Bridge is an ultra-wide double-sided steel box girder with $48.5 \mathrm{~m}$ wide, and the length of standard segments is $19.8 \mathrm{~m}$. The transverse center to center spacing between the two box longitudinal girders of the main girder is $40 \mathrm{~m}$, and the height of the beam at the center of the standard section is $3.1 \mathrm{~m}$. The thicknesses of the top, bottom, and web plates of the box longitudinal beams are both $16 \mathrm{~mm}$. Furthermore, the top and bottom plates are provided with $180 \mathrm{~mm}$ (wide) $\times$ $16 \mathrm{~mm}$ (thick) plate stiffening ribs, and the web is equipped with $165 \mathrm{~mm}$ (wide) $\times 14 \mathrm{~mm}$ (thick) plate stiffening ribs. A diaphragm is arranged every $3.3 \mathrm{~m}$ inside the box girder, and the thickness of the diaphragms is $14 \sim 30 \mathrm{~mm}$. To ensure the good integrity of the main girder, the double-sided box girders are connected by crossbeams, and the spacing between the crossbeams is $3.3 \mathrm{~m}$. The crossbeam adopts I-shaped section, the width of the bottom plate is $600 \mathrm{~mm}$, and the thickness of the bottom and web is $16 \sim 28 \mathrm{~mm}$ and 
TABLE 1: The differences between the ultra-wide double-sided steel box girders and common box girders.

\begin{tabular}{|c|c|c|}
\hline & Ultra-wide double-sided steel box girder & Common steel box girder \\
\hline Deformation & $\begin{array}{c}\text { The deformation of deck center is greater than } \\
\text { the sides. }\end{array}$ & The deformation of deck at each box center is greatest. \\
\hline Top plate stress & $\begin{array}{c}\text { There are obvious shear lag effect and fatigue } \\
\text { stress. }\end{array}$ & The shear lag effect is slightly smaller than the former. \\
\hline $\begin{array}{l}\text { Torsional } \\
\text { performance }\end{array}$ & It has excellent torsional resistant performance. & $\begin{array}{l}\text { It also has good torsional resistant performance, but it is smaller } \\
\text { than the former. }\end{array}$ \\
\hline Design focus & $\begin{array}{l}\text { The shear lag effect, fatigue damage, and } \\
\text { crossbeams. }\end{array}$ & The overturning resistance, stiffening ribs, and crossbeams. \\
\hline
\end{tabular}

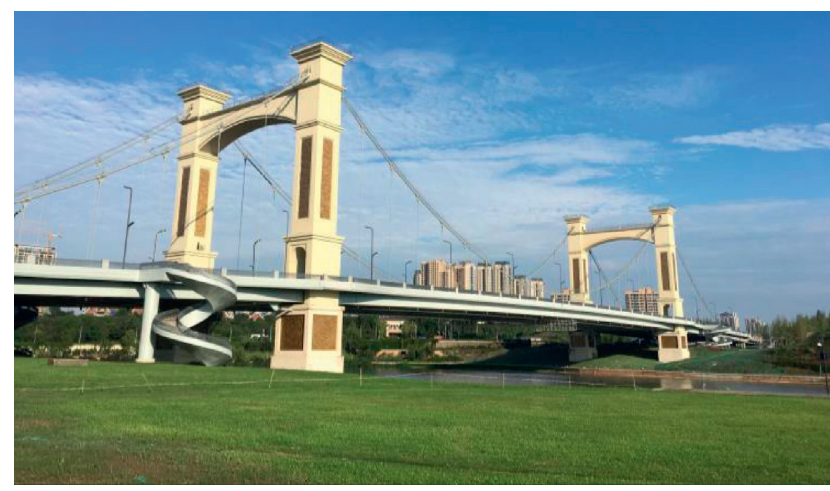

Figure 1: View of the Yunlongwan Bridge.

$14 \mathrm{~mm}$, respectively. The web is equipped with horizontal and vertical stiffening ribs. The top plate of the crossbeam is the bridge deck, its thickness is $16 \mathrm{~mm}$, and the bridge deck is reinforced by U-shaped stiffening ribs. A cross-sectional view of the ultra-wide double-sided steel box girder is shown in Figure 3.

\subsection{Full-Scale Field Test}

2.3.1. Experimental Overview. In order to study the working performance of suspension bridge and explore the actual mechanical behaviour of ultra-wide double-sided steel box girder in practical use, the full-scale field test load was carried out on this bridge in this study. The finite element model of the Yunlongwan Bridge was established by Midas Civil software, and the spatial analysis and calculation of the bridge was carried out. The finite element model consisted of 152 beam elements and 130 tension-only bar elements, in which the main beam adopted beam elements, and the main cables and suspenders employed tension-only bar elements. The calculation model is shown in Figure 4. Based on the bridge design data and model calculation results, the loading scheme of the load test was designed.

In the light of the loading scheme, the bridge was loaded. After the deformation of the bridge was stable, the displacement or stress of each measuring point and the internal force of the suspenders were measured, and the changes of the bridge were observed. By comprehensively analysing the test data and the bridge changes, the working performance of the bridge and the mechanical behaviour of the main girder could be revealed. At the same time, the deficiencies of the double-sided steel box girder such as large torsional deformation and shear lag effect could be found to provide reference for the construction of similar girder in the future. The full-scale field test could also provide the most direct reference for the finite element simulation analysis of the bridge. To be specific, the accuracy of the finite element model could be judged by comparing the field test data with the calculation results of the finite element model [20]. In the process of the field static load test, in order to prevent accidents due to insufficient bearing capacity of the bridge, the bridge was loaded step by step to the maximum load and the load step was set at $300 \mathrm{kN}$.

2.3.2. Layout Scheme of Measuring Points. The main test terms were the deflection distribution of the bridge, the internal forces of suspenders, and the stress of key sections of main beam under different loading conditions. For obtaining the longitudinal distribution of bridge deflection, 39 measuring points were set up in the upstream and downstream of the bridge, respectively. In the transversal direction, these measuring points of each side are on the inside of the suspender, which were away from the suspenders $20 \mathrm{~cm}$. And in the direction of the longitudinal bridge, they were distributed on the longitudinal bridge at each suspender, anchoring point, bridge tower, and the middle and end of the first span of the approached bridge. The specific layout locations of these measuring points are shown in Figure 5(a). And 10 measuring points were arranged in the midspan 1/2 section (Section 1-1) to get the transverse deflection distribution, as shown in Figure 5(b). The Leica Level (NA02) was used to measure the elevation of each measuring point, and the deflection value could be obtained by subtracting the elevation values before and after loading. And the elevation datum point of this bridge was taken as the reference point with zero displacement.

Except for the deflection of the main girder, the internal force increment of the suspenders was also an important factor to judge the overall mechanical behaviour of suspension bridge. In this test, a total of 10 suspender force measuring points were set up, which were located on ten suspenders in the middle of the upstream and downstream, that was, U14-18 and D14-18 suspenders, in which U and D represented the upstream and downstream, respectively, and the number indicated the serial number of suspenders. The cable force tester was used to measure the internal force increments of the 10 middle suspenders under different working conditions according to the principle of the chord vibration method. 


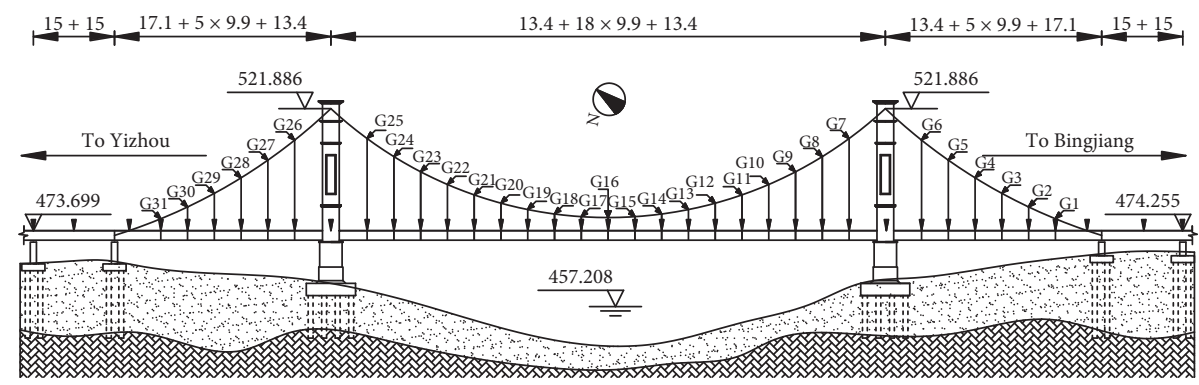

Figure 2: Elevation view of the Yunlongwan Bridge (unit: $\mathrm{m}$ ).

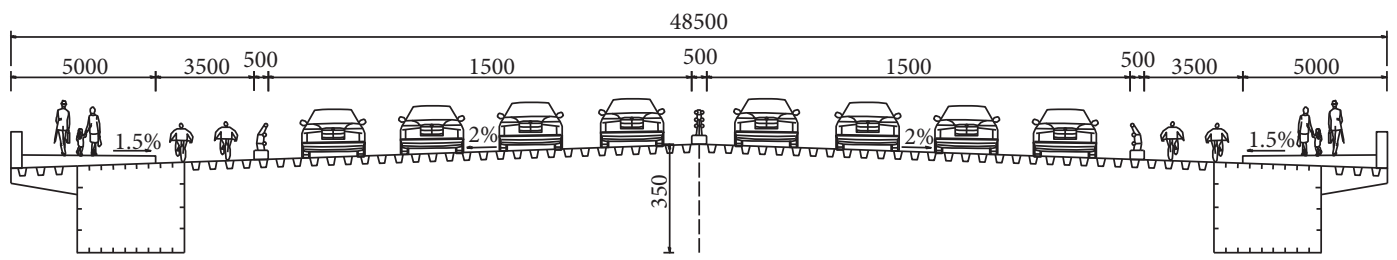

Figure 3: The cross-sectional view of the ultra-wide double-sided steel box girder (unit: $\mathrm{mm}$ ).

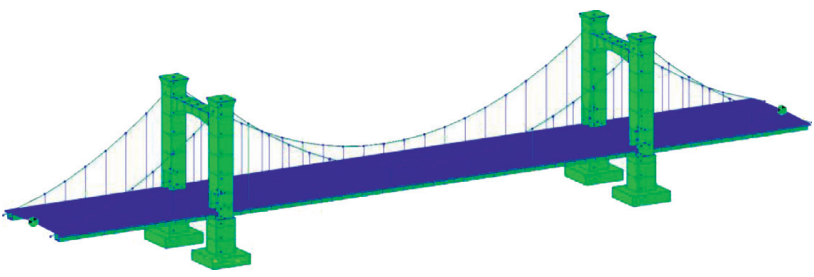

Figure 4: Finite element model of the Yunlongwan Bridge.

Because the mechanical behaviour of the ultra-wide double-sided steel box girder was complex and there was little research at present, this study specially studied the mechanical behaviour of this kind of girder and focused on its shear lag effect. To accurately measure the stress distribution of the main girder and research the influence of suspender and crossbeam on the force of the main girder, three cross sections of the girder near the middle of the midspan were selected, and 29 stress measuring points were arranged on the bottom side of top plates of each selected section. The three selected sections were the midspan $1 / 2$ section (Section 1-1), section $3.3 \mathrm{~m}$ away from Section 1-1 (Section 2-2), and section $5 \mathrm{~m}$ away from Section 1-1 (Section 3-3). Both Sections 2-2 and 3-3 were located on the side near Yizhou Road. There are suspenders and crossbeam at Section 1-1, no suspenders but crossbeam at Section 2-2, and neither suspenders nor crossbeam at Section 3-3. The schematic diagram of selected section and the arrangement of stress measuring points are shown in Figure 6.

2.3.3. Loading Conditions. According to the "Highway Bridge Load Test Regulations" JTG/T J21-01-2015, when the load test is carried out on the completed bridge, the load efficiency should be between 0.85 and 1.05 [21]. Combined with the structural characteristics of the bridge and the model calculation results, 16 triaxial trucks with a mass of about $30 \mathrm{t}$ were used as loading vehicles. The front, middle, and rear axle masses of the loaded vehicle are $6 \mathrm{t}, 12 \mathrm{t}$, and $12 \mathrm{t}$, respectively. And the loaded wheel spacing is shown in Figure 7.

In the test, three loading conditions were set, namely, symmetrical loading of midspan $1 / 2$ section (Condition 1 ), eccentric loading of midspan $1 / 2$ section (Condition 2 ), and symmetrical loading of midspan $1 / 4$ cross section (Condition 3 ). The layout of loading vehicles under each condition is shown in Figure 8. After the loading vehicle was loaded in place in accordance with the sequence, the engine should be shut down and the test data should be collected after the bridge deformation was stable.

\section{Experimental Results and Analysis}

3.1. Bridge Integral Deformation. So as to understand the overall working performance of the bridge, the longitudinal and transverse distribution of bridge deflection were analysed. First of all, the longitudinal distribution of bridge deflection was studied. Under the condition of symmetrical loading, the deflections at the same position of the upstream and downstream of the bridge were almost the same, so the average deflection of the upstream and downstream of the bridge in the same position was taken as the deflection value of this position. Under the condition of eccentric loading, the deflections of the upstream and downstream of the bridge were quite different, so the deflection values of the upstream and downstream were given, respectively. Then, the transverse distribution of the bridge deflection was analysed. Based on the longitudinal and transverse distribution of bridge deflection, the overall deformation performance of the bridge was judged.

Figure 9 shows the longitudinal distribution of the test values of the deflection of the bridge under three loading conditions. It can be seen from the figure that the measured maximum deflection of the main beam under the three loading conditions is $110.876 \mathrm{~mm}, 88.87 \mathrm{~mm}$, and 


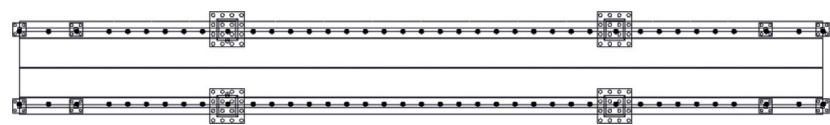

- Deflection measuring point

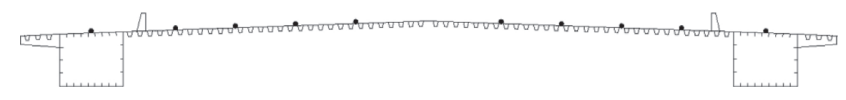

- Deflection measuring point

(b)

FIgURE 5: Layout of deflection measuring points. (a) The measuring points of deflection longitudinal distribution. (b) The measuring points of deflection transverse distribution.

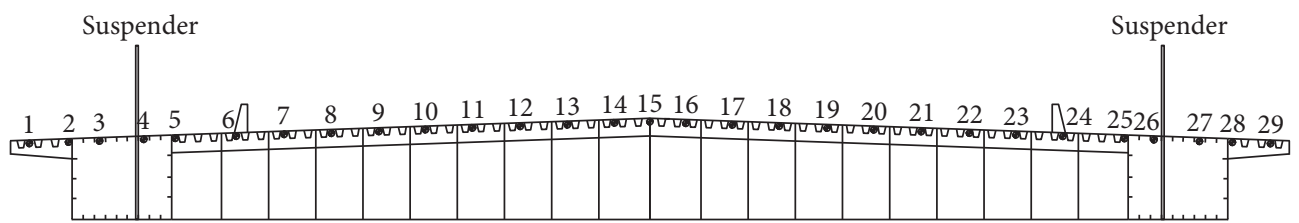

(a)

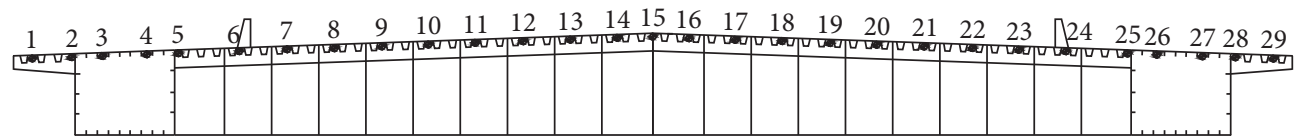

(b)

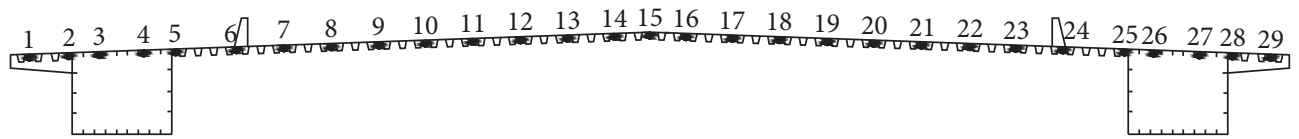

(c)

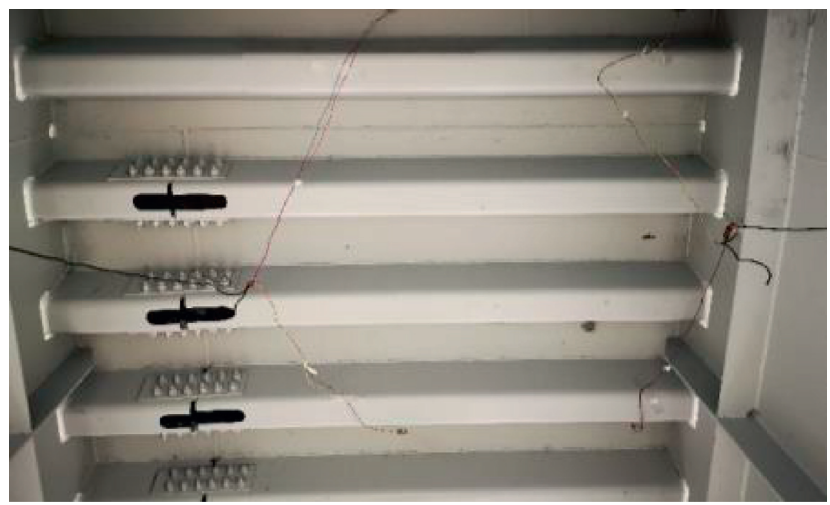

(d)

FIGURE 6: Selected cross sections and layout of measuring points. (a) Section 1-1. (b) Section 2-2. (c) Section 3-3. (d) Stress measuring points.

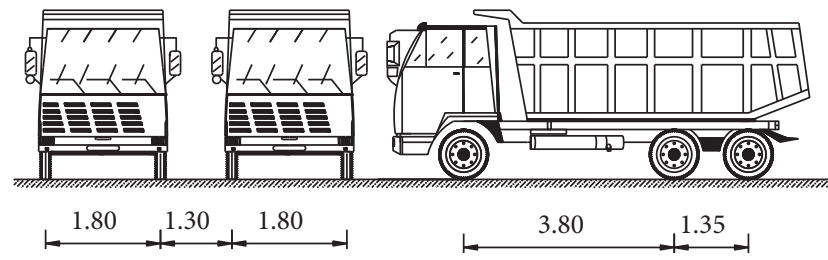

Figure 7: The wheel distances of loading vehicles (unit: $\mathrm{m}$ ).

$77.63 \mathrm{~mm}$, respectively. The maximum deformation of the bridge is less than the allowable value $820 \mathrm{~mm}$ [22], indicating that the bridge capacity meets the requirements. Under the action of the load on $1 / 2$ section (Conditions 1 and 2), the vertical deflection of the main beam changes in a V shape from the section of the G15 suspender in the middle of the span to both ends of the bridge, and the trend to both ends is the same. However, under the action of the load on $1 / 4$ section (Condition 3 ), the loading place is bent downward, while the $1 / 4$ cross section at the other end of the bridge is arched upward, and the overall deformation of the bridge is S-shaped. From the longitudinal distribution shape of the deflection, it can be known that the overall symmetry of the bridge is good, and the main girder of the bridge has a good overall longitudinal stiffness. When the bridge is subjected to the eccentric load on the $1 / 2$ section, the deflection of the loaded side (downstream) is much larger than that of the unloaded side (upstream). The maximum measured values of upstream and 

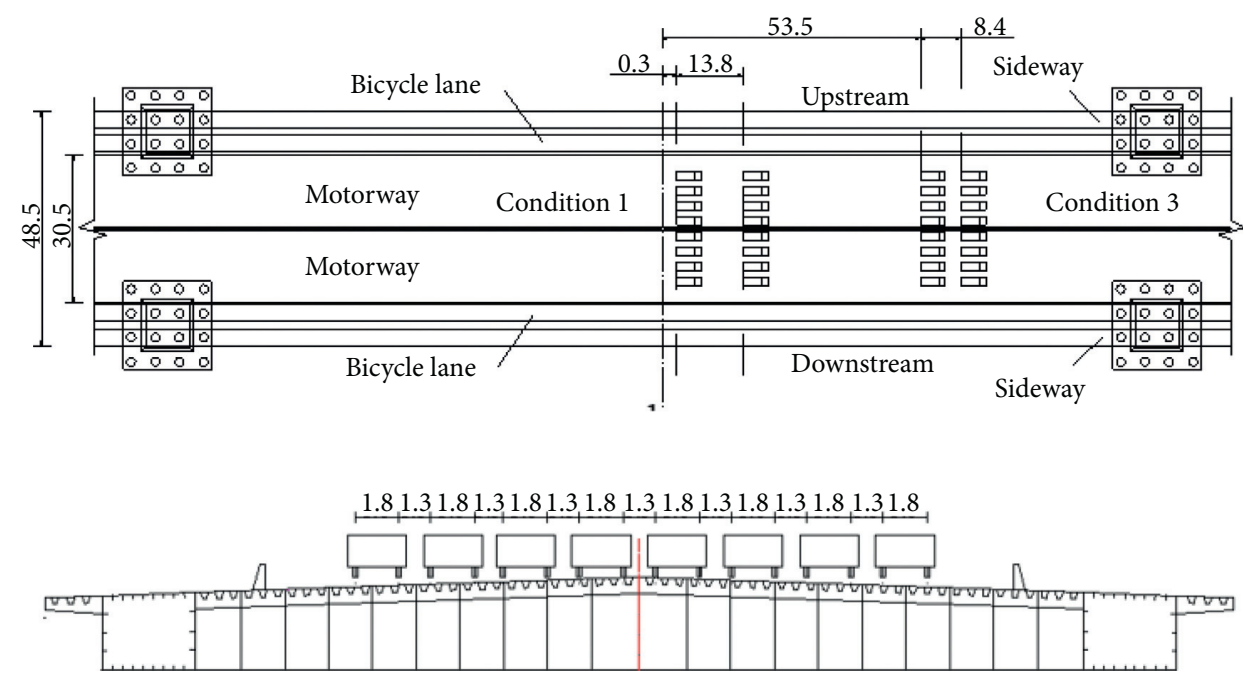

(a)
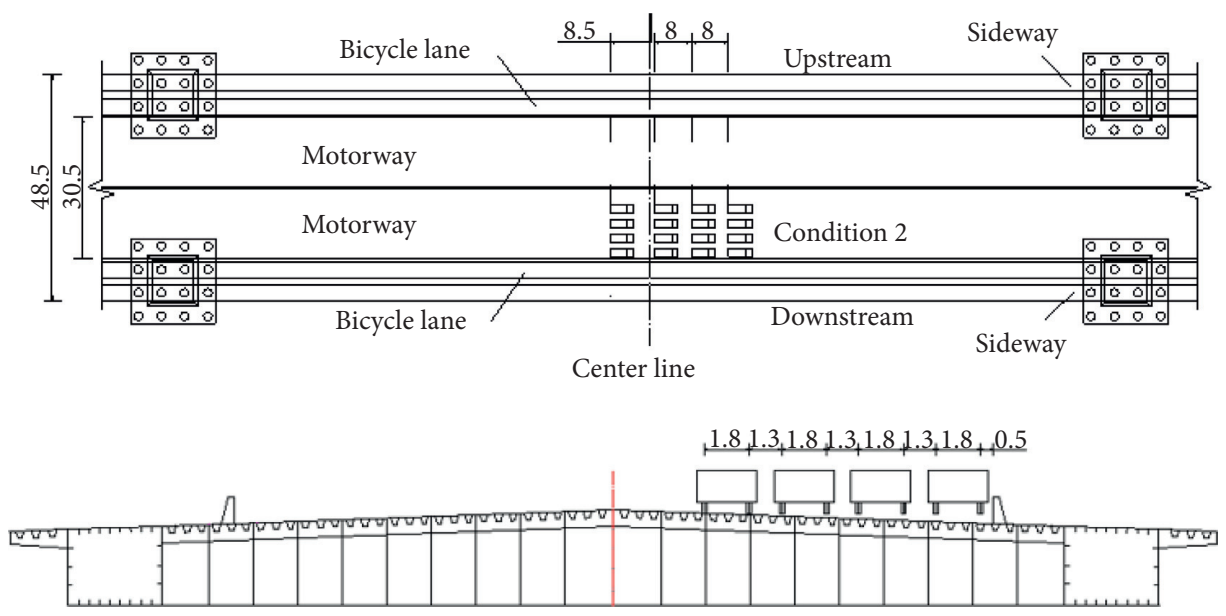

(b)

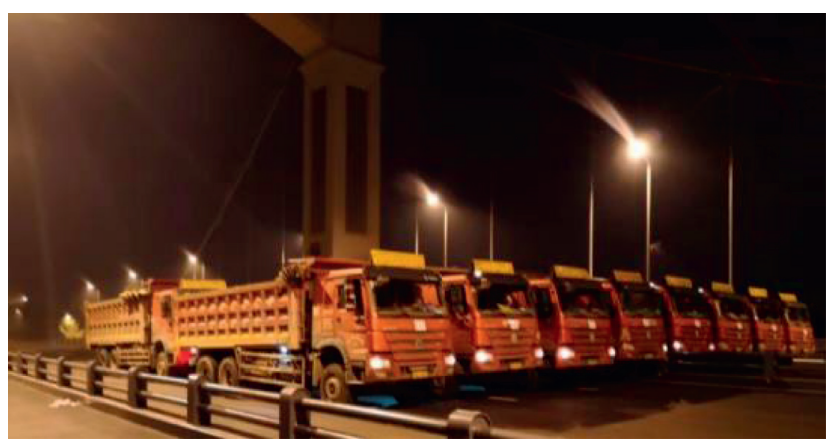

(c)

Figure 8: Layout of loading vehicles (unit: m). (a) Symmetrical loading (Conditions 1 and 3). (b) Eccentric loading (Condition 2). (c) Full-scale field test.

downstream deflections are $32.35 \mathrm{~mm}$ and $77.63 \mathrm{~mm}$, respectively, and the main girder of the middle span has obvious torsional deformation. This phenomenon indicates that eccentric loading is detrimental to the torsion of ultra-wide double-sided steel box girders, which should be avoided as much as possible in practice.

Figure 10 shows the experimental values of lateral distribution of deflection of $1 / 2$ cross section under the symmetrical loading and eccentric loading on 1/2 section (Conditions 1 and 2). In the case of symmetrical loading, the transverse distribution curve of deflection is close to a horizontal straight line, but the deflection in the middle is slightly greater than the deflection on the sides. This is caused by the box girder on both sides. The middle part of the top plate is far away from the box girder, and so its stiffness is smaller and its deflection is larger. If the deflection of the top plate middle part is too large, the cross 


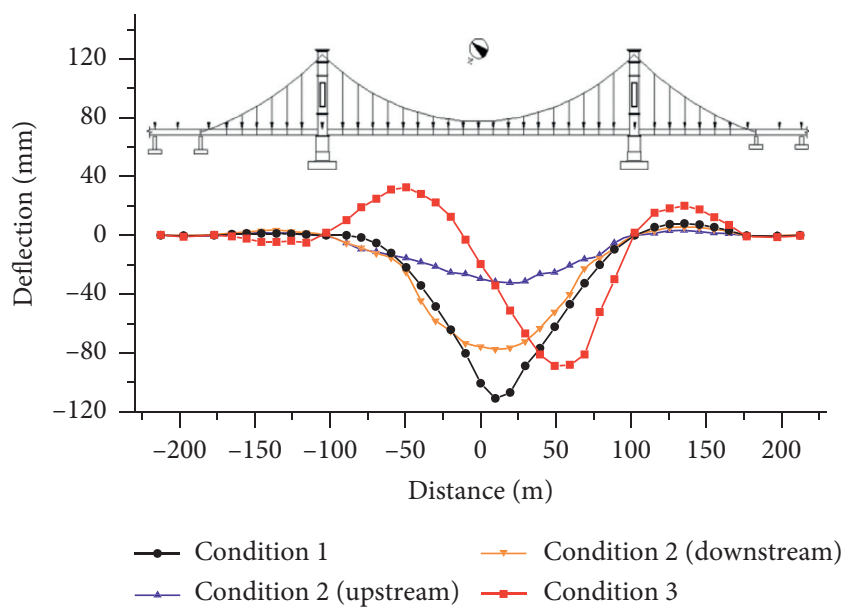

Figure 9: Longitudinal distribution of deflection.

slope of the bridge deck would be offset, which may cause stagnant water on the bridge deck, accelerate the corrosion of the steel girder, and affect the driving safety. The deformation in the middle of the top plate of the ultra-wide double-sided steel box beam has a greater impact on the structure. In the case of eccentric loading, except for the deflection of two box girders, the transverse distribution curve of deflection is close to an oblique line. In the case of eccentric loading (Condition 2), except for the deflection of two box girders, the transverse distribution curve of deflection is close to an oblique line. This indicates that the overall stiffness of the top plate is good, and the deformation could be consistent. However, the stiffness of the box girder on both sides is greater than that of the top plate, and the deflection of the steel beam has a sudden decreasing trend relative to the deflection of top plate. This leads to a large difference in deflection between the left and right sides of the top plate close to the steel beam, and the deformation of this segment of the top plate would be greater than that of other parts.

3.2. Internal Force of Suspender. The cable force tester was used to measure the internal force increments of the ten middle suspenders under different working conditions to study the load distribution of bridges. The measured result of internal force increment of each suspender is shown in Figure 11, in which each suspender number indicates two suspenders, and $U$ and $D$ represent the upstream and downstream suspenders, respectively. The No. 16 suspenders are the middle suspenders. Under the action of symmetrical load (Conditions 1 and 3), the internal force increments of the suspenders on both sides of the upstream and downstream cable planes are very close, indicating that the bridge has good lateral symmetry and so the lateral load distribution is more uniform. While under the eccentric load (Condition 2), the internal force increments of the downstream suspenders are obviously greater than that of the upstream suspenders. The difference of the No. 16 suspenders is the smallest $(91.2 \mathrm{kN})$, and the difference of the No. 15 suspender is the largest $(210.6 \mathrm{kN})$. The results show that under the eccentric load, the force on both sides of the cable plane is obviously uneven, and

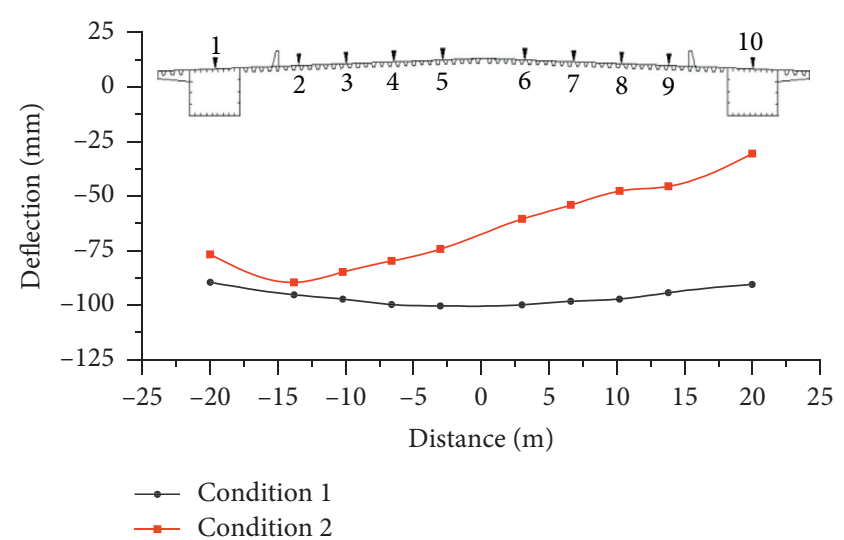

Figure 10: Lateral distribution of deflection.

the main beam would have obvious torsion, which corresponds to the deflection transverse distribution of the main beam under the eccentric load. The internal force increment at the middle suspenders is smaller than that of the other suspenders, while the internal force increments of the first suspenders near the middle suspenders (No. 15 and No. 17) are larger. This illustrates that the load of the suspenders near the middle is larger than that of the middle suspenders, so in the actual use of the bridge, it is necessary to pay attention to the suspender with great change of internal force near to the middle suspenders.

\subsection{Longitudinal Stress of Ultra-Wide Double-Sided Steel Box} Girder. To understand the internal force distribution of ultra-wide double-sided steel box girder more clearly, the longitudinal stresses of the top plate of the main girder on Section 1-1 under three loading condition were measured during the test. From Figure 12, it can be seen that the whole top plate is subjected to compressive stress under Conditions 1 and 2, while it is subjected to tensile stress under Condition 3. This illustrated that in the actual use of the bridge, when vehicles pass through the bridge, the top plate would be subjected to alternating stress, which is easy to cause fatigue damage [23]. As the loading point is far away with Section 11 under Condition 3, the longitudinal tensile stress is not big. Large longitudinal tensile stresses may occur in the section if the loading point is near. Hence, the fatigue problem of the bridge under load is also worthy of attention. It also can be seen that the absolute value of stress at the intersection of the web and top plates of the box girder suddenly increases, which indicates that the shear lag effect appears obviously in the ultra-wide double-sided steel box girder under load [24]. Therefore, measures need to be taken at the junction of web and top plates to prevent structural damage caused by excessive stress.

\subsection{Shear Lag Effect of Ultra-Wide Double-Sided Steel Box} Girder. From the previous section, it is shown that there is an obvious shear lag effect in the ultra-wide double-sided steel box girder under test load. In this section, the shear lag effect of Section 1, 2, and 3 under Condition 1 was compared and analysed to further explore the variation law and 


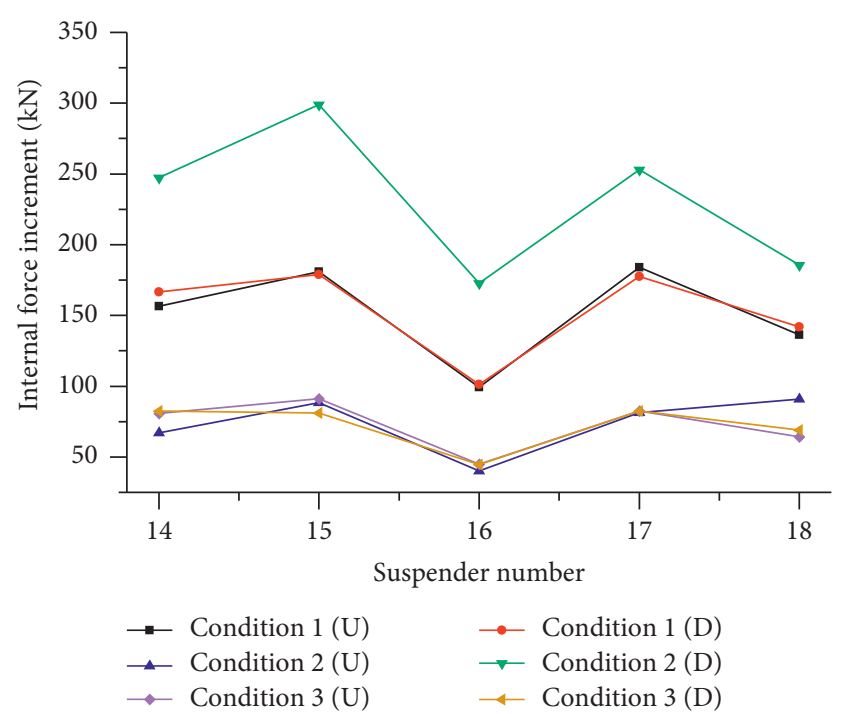

FIGURE 11: Internal force increments of suspenders.

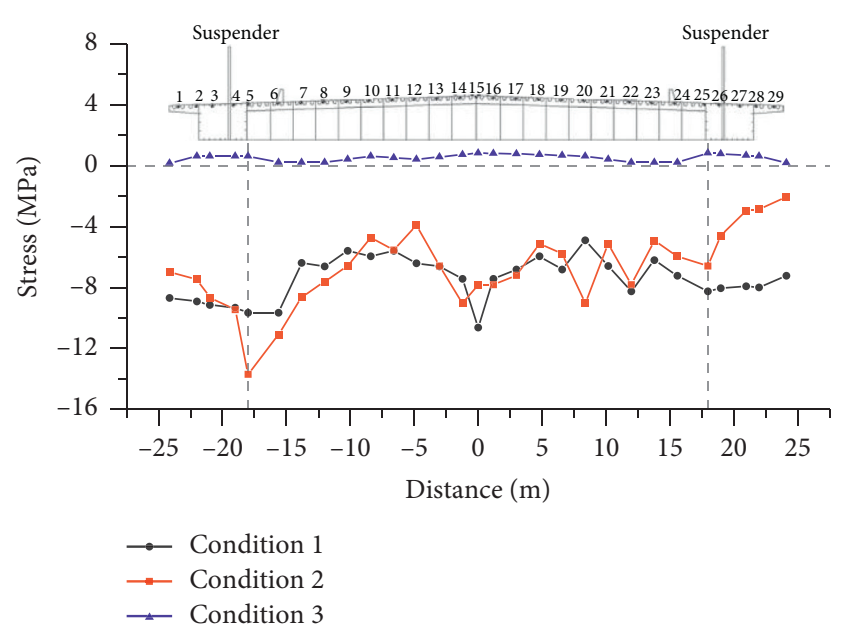

FIgURE 12: Longitudinal stress distribution of top plate.

influence factors of shear lag effect of the girder. The stress data collected from the test were processed and calculated, and the shear lag coefficient $\lambda$ of each measuring point on the top plate was obtained. The shear lag coefficient is calculated according to the following formula [25]:

$$
\begin{aligned}
& \lambda=\frac{\sigma_{n}}{\bar{\sigma}}, \\
& \bar{\sigma}=\sum_{i=1}^{29} \sigma_{i},
\end{aligned}
$$

where $\sigma_{n}$ is the normal stress of the calculated point, $\bar{\sigma}$ is average stress, and $\sigma_{i}$ is the stress of measuring point $i$. The calculated results are shown in Figure 13.

The transverse distribution of the shear lag coefficient of three selected sections is seen under the action of Condition 1 from Figure 13. The distribution law of the shear lag coefficient of the three sections is roughly the same, the shear lag coefficient suddenly increases at the

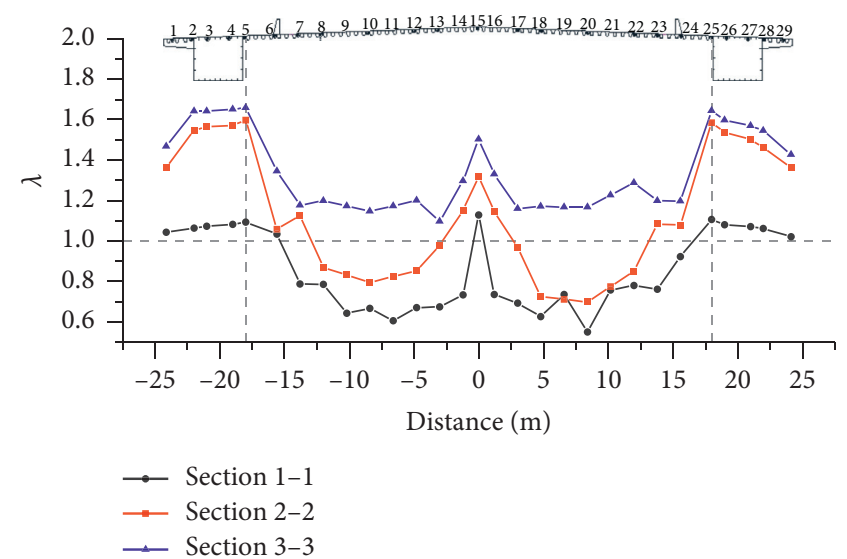

FIgURE 13: Shear lag coefficient.

middle point of the top plate and the intersection of the top plate and the web, and the shear lag coefficient is positive in these parts. This is due to the transverse slope of the bridge deck and the abrupt change of the cross section caused by the box girders on both sides. In addition, the existence of suspenders and crossbeam would have a certain influence on the distribution of shear lag coefficient of ultra-wide double-sided steel box girder. On the control section without suspender and crossbeam (Section 3-3), the shear lag coefficient is positive, while there is an alternation of positive and negative shear lag on the control section without suspender but with crossbeam (Section 2-2) and on the control section with suspender and crossbeam (Section 1-1). The shear lag coefficient reaches its peak at the junction of box girder and top plate on both sides and shows positive shear lag in this range. However, the shear lag coefficient of Section 11 is less than that of Section $2-2$ as a whole. It is obvious that the suspenders and crossbeam changed the stress of the girder, thus changing the shear lag effect of the cross section. By comparing the changes of the shear lag coefficient of different sections, it can be known that when the crossbeam or suspenders are added on the cross section, the peak value of the transverse shear lag coefficient would decrease significantly, and the negative shear lag phenomenon would also occur in the cross section. However, the overall change law of the shear lag coefficient would not change obviously.

Due to the existence of shear lag effect, the concept and calculation method of the effective flange width of box girder are given in AASHTO code [26]. The widthspan ratio of the Yunlongwan Bridge is $b / \mathrm{l}=48500$ / $205000 \approx 0.2366$. According to section 4.6.2.6.2 in AASHTO, the effective width ratio is about 0.665 , which is equivalent to the shear lag coefficient of $1 / 0.665=1.504$. In this test, the average shear lag coefficient of Section 3-3 at the webs of two side girders is 1.65138 . This indicates that the shear lag coefficient calculated by AASHTO is slightly smaller than the test. Therefore, the effective flange width should be appropriately reduced in the stress calculation of the ultra-wide double-sided steel box girder. 


\section{Establishment of Multiscale Model and Parametric Analysis}

Figure 14 shows the cracking of the bridge deck pavement just after the Yunlongwan Bridge opened to traffic. It can be seen that serious cracks occurred in the carriageway, resulting in the forced rework of this bridge. It is preliminarily speculated that the overloading was serious, and the excessive longitudinal and transverse tensile stress of the bridge deck led to the cracking of the asphalt pavement. In general, there are many factors which could bring about the excessive stress of the bridge deck, and in addition to the increasingly serious overloading problem, the U-rib thickness and diaphragm spacing among the design factors would also have some influence. In response to this problem, the multiscale finite element model of the Yunlongwan Bridge was established by ANSYS finite element software, based on which the influence of various parameters on the maximum stress of bridge section under Condition 3 was studied.

4.1. Establishment and Verification of Multiscale Model. The structure of the Yunlongwan Bridge is described in Section 2.1. Because of the need for accurate analysis of some areas of the double-sided steel box girder in this model, they are spatial plate and shell structures and simulated by SHELL63 element. This element has a total of four nodes, each node includes six degrees of freedom, and has the properties of bending and membrane at the same time, so it can withstand in-plane load and normal load. The remaining double-sided box steel girder, crossbeam, diaphragm, and concrete tower column in the model are nonkey analysis areas, and in order to simplify the calculation, they are bar structure and simulated by BEAM4 element. This element has a total of two nodes, each node includes six degrees of freedom, and it is a kind of element which can analyse tension, compression, bending, and torsion. For the rigid arm constrained by the sling point and the main beam, the BEAM4 element is also used to simulate. The material density of rigid arm is 0 , and the elastic modulus is assigned to the maximum value to reflect its unbendable deformation. In general, the elastic modulus of the rigid arm is 1000 times that of steel, but the value should not be too large, which is because excessive elastic modulus of the rigid arm would cause the deformity of the stiffness matrix and affect the accuracy of the calculation results to a certain extent. Because the slings and main cables in the model only bear the axial force, the LINK10 element is used to simulate them. This element has two nodes, and each node has three translational degrees of freedom. It is a kind of bar element which is only subjected to tension or compression in the axial direction, and thus, it is suitable for the simulation of stay cables, suspension cables, and other structures. When simulating the sling and the main cable, it is necessary to use KEYOPT ( 3$)=0$ to ensure that they are only under tension. The above finite elements were commonly used in suspension bridge model, and their types of interpolation and integration are shown in Table 2. Based on the above analysis, the selection of unit types and real constants during

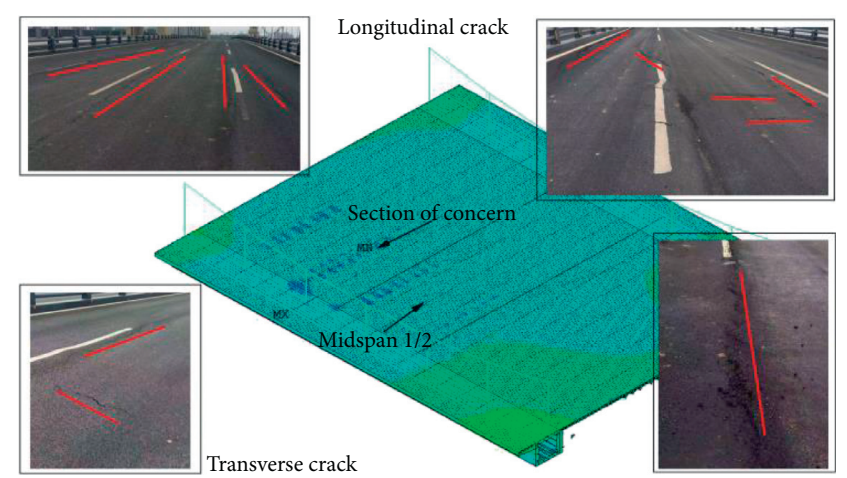

Figure 14: Cracks in the Yunlongwan Bridge deck pavement.

the process of establishing the bridge model is shown in Table 3. In addition, in this multiscale mode, the nodes at the bottom of towers and the main girder contacted with piers were constrained, and only the rational DOFs at $y$ direction of the main girder notes were released. The suspenders were connected with the main cables and girders by corporate nodes. In the small-scale model at the midspan, the two side box girders were connected with the top plate by rigid arm.

Based on the above information, the multiscale finite element model of the Yunlongwan Bridge was established, as shown in Figure 15. In this model, the length of the plate and shell in the middle span of the main bridge is $60 \mathrm{~m}$, and the rigid domain method (CERIG) is used for the beam-shell connection. The partial grid density of the main beam of the shell element is $0.2 \times 0.2 \mathrm{~m}$, and that of the crossbeam and diaphragm is $0.5 \times 0.5 \mathrm{~m}$. Because of the irregular U-ribs, the crossbeam is divided by free mesh. The application of vehicle load in the model was realized by the SF command of applying surface load to the node group, so it is necessary to determine the local wheel pressure area of the bridge deck. The loading areas were consistent with the test conditions. The thickness of the bridge deck pavement is $9 \mathrm{~mm}$, and the contact area between the wheel and the bridge deck is $0.2 \times 0.6 \mathrm{~m}$; the contact surface spreads at an angle of $45^{\circ}$ from the bridge deck pavement to the top of the steel box girder as shown in Figure 16. In the subsequent analysis and calculation, the analysis type of static elastic analysis was adopted.

After the establishment of the model, the deflection of the bridge and the stress distribution of Section 1-1 under the action of Condition 1 were calculated by the model and the static elastic type was adopted. The comparison between the calculated result and the experimental result is shown in Figure 17. It can be seen that the calculated values in the figure are very close to the experimental values. It is shown that the established model has a good accuracy and could accurately simulate the force of the bridge. Therefore, the finite model could be used for force calculation and parameter analysis of the bridge.

According to the simulation results, this paper selects the top plate section at the target section and the adjacent crossbeam sections on the left and right sides (the left section is between the third row and the fourth row, and the right section is between the front and rear wheels of the third 


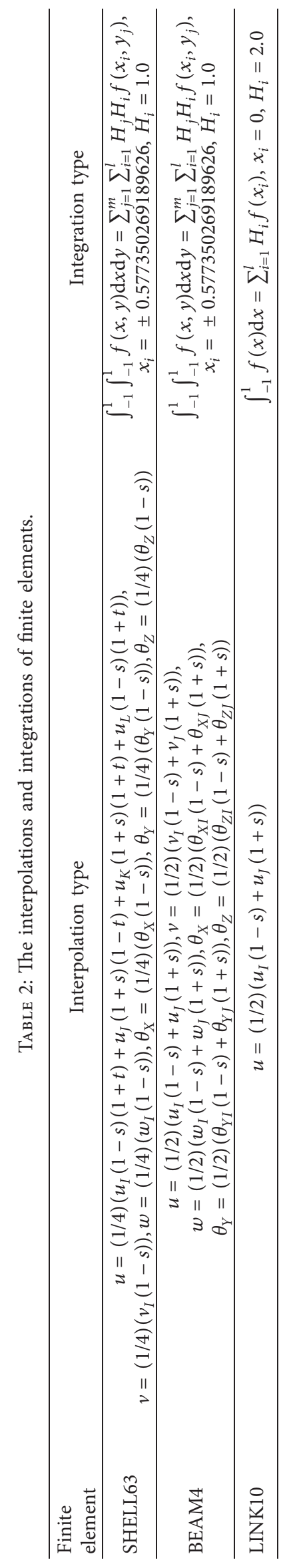


TABLE 3: Specific information of the finite element model.

\begin{tabular}{lccc}
\hline Material & Position & Elastic modulus (MPa) & Unit type \\
\hline C50 & Tower column, upper beam & $3.45 e 4$ & BEAM4 \\
Q345D & Fish bone girder & $2.05 e 5$ & BEAM4 \\
Q345D & Plate and shell girder & $2.05 e 5$ & SHELL63 \\
Wire1770 & Sling, main cable & $2.05 e 5$ & LINK10 \\
Q345 & Rigid arm & $2.05 e 8$ & BEAM4 \\
\hline
\end{tabular}

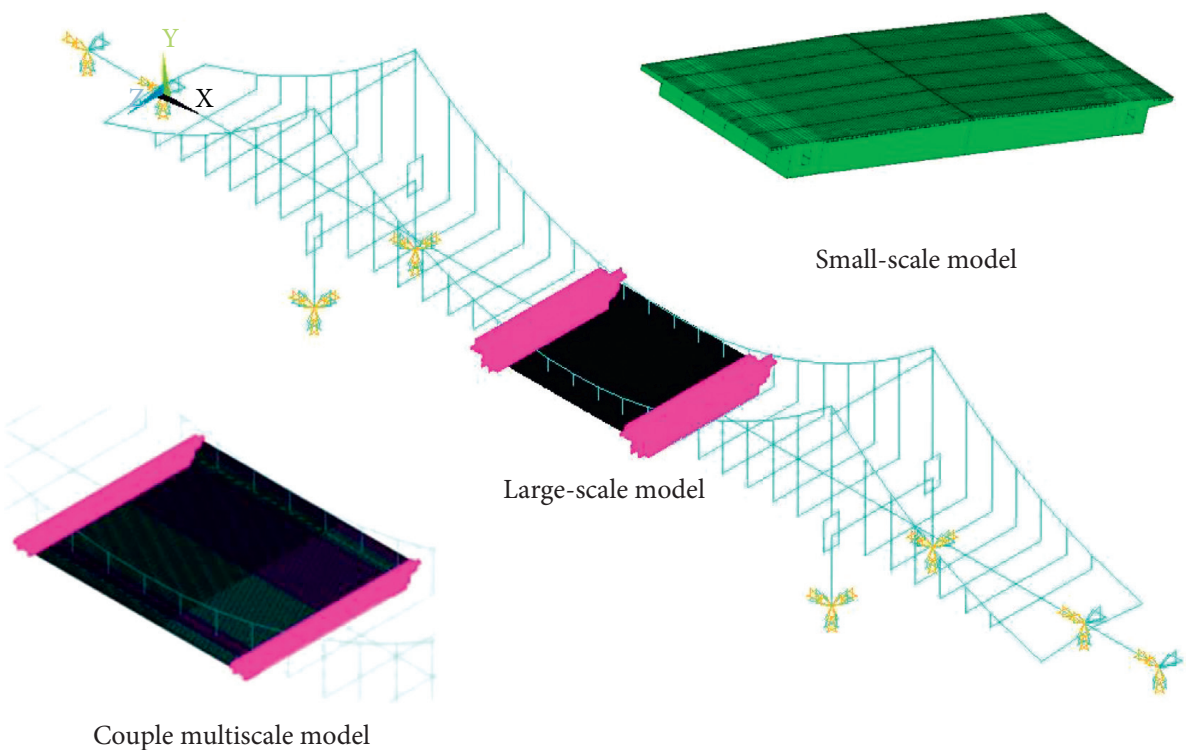

Figure 15: Multiscale model of full-bridge.

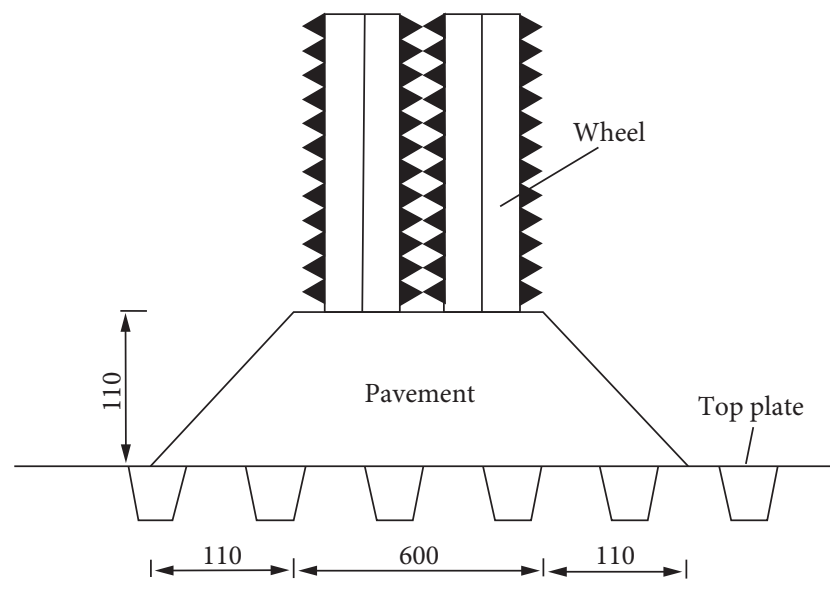

FIGURE 16: Schematic diagram of vehicle wheel pressure area diffusion (unit: $\mathrm{mm}$ ).

row). By changing the parameters in the ANSYS model, the influence of U-rib thickness, beam spacing, and vehicle axle load on the maximum stress of the top plate of the target section was studied, which could provide some guidance for bridge design and operation.

4.2. Change of U-Rib Thickness. The change of U-rib thickness would affect the longitudinal stiffness of the bridge deck. When the stiffness of the beam is large and the beam has small deformation, the bending stress or deformation caused by the axial force can be ignored, and the total stress can be calculated according to the superposition principle. The bending normal stress in the beam would decrease with the increase of stiffness; hence, it can be seen that the U-rib stiffness could affect the longitudinal normal stress of the top plate.

The change of the maximum top plate stress in $X$ direction of each section with the increase of the thickness of U-rib was extracted from the model as shown in Figure 18. It can be seen from the figure that the maximum tensile and compressive stresses of the top plate at the three sections all decrease to a certain extent with the increase of the thickness of U-ribs. And the maximum stress decreases rapidly when the U-rib thickness increase from $2 \mathrm{~mm}$ to $4 \mathrm{~mm}$. Specifically, the maximum tensile and compressive stresses at the top plate of the target section decrease most significantly, and the former decreases from $18.7 \mathrm{MPa}$ to $8.3 \mathrm{MPa}$, decreasing by $55.6 \%$, while the latter decreases from $31.1 \mathrm{MPa}$ to $22.3 \mathrm{MPa}$, decreasing by $28.3 \%$. The stress curves tend to be flat after the U-rib thickness reaches $4 \mathrm{~mm}$ and basically stable after $8 \mathrm{~mm}$. This phenomenon shows that the increase of U-rib thickness can effectively reduce the maximum stress of the top plate at the section where the wheel acts. However, the beam weight would increase with the U-rib thickness. When the thickness of the U-rib is too thick, increasing it 


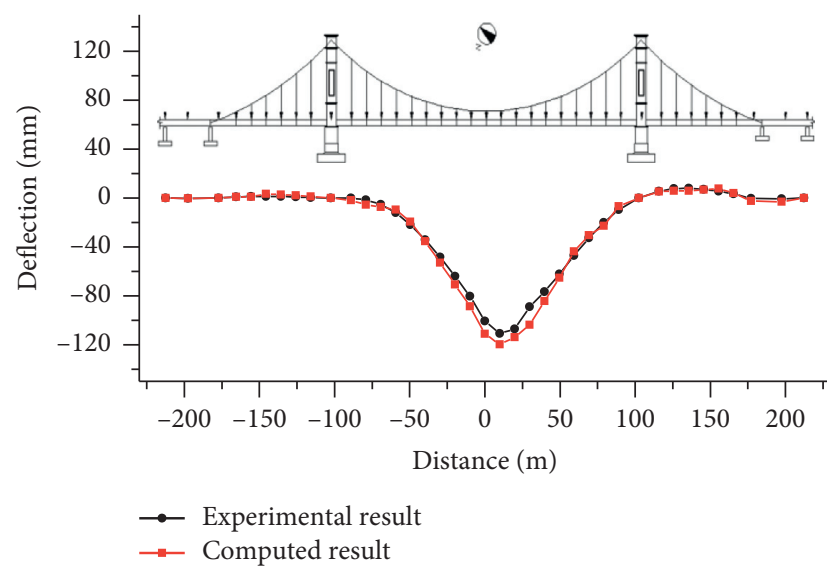

(a)

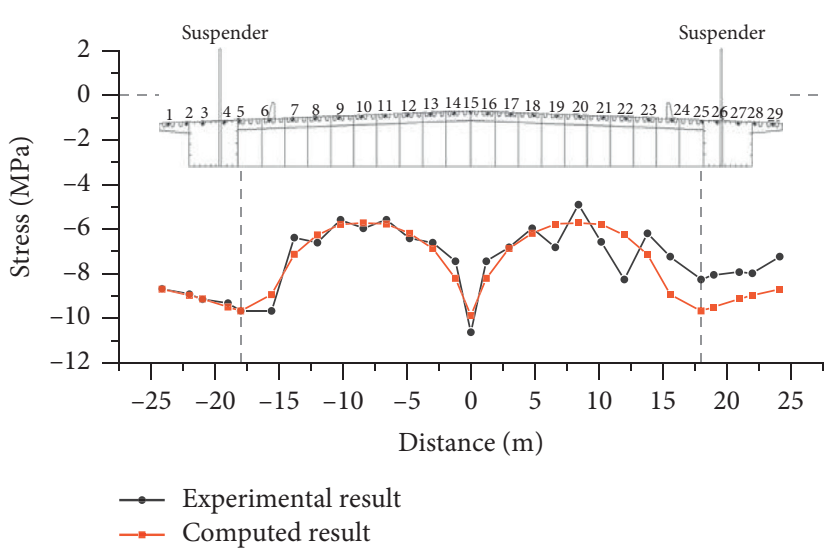

(b)

Figure 17: Comparison between experimental result and computed result. (a) Longitudinal distribution of deflection. (b) Longitudinal stress.

continuously has no significant effect on improving the stress state of the beam.

In Figure 18, $X$ denotes the $X$ direction; $\mathrm{L}, \mathrm{U}$, and $\mathrm{R}$ denote the left, target, and right sections, respectively; and $\mathrm{T}$ and $\mathrm{C}$ denote the tensile and compressive stress, respectively.

There are not only $X$-direction cracks but also $Z$-direction cracks in bridge deck pavement. According to the model, the $Z$-direction stress is mainly tensile, and the compressive stress is very small, so only the variation of the maximum tensile stress with U-rib thickness was extracted from the model as shown in Figure 19. It can be seen from the figure that the maximum top plate tensile stress at target section is relatively large, exceeding $22 \mathrm{MPa}$, and the effect of changing the thickness of the U-rib on the tensile stress is more obvious. When the thickness of the U-rib increases from $2 \mathrm{~mm}$ to $6 \mathrm{~mm}$, the stress decreases significantly, from 24.7 MPa to $22.4 \mathrm{MPa}$, a decrease of $9.3 \%$. However, compared with the cross section of the adjacent beam, the stress is still very large. After $6 \mathrm{~mm}$, the effect of the increase of U-rib thickness on the maximum stress is not obvious. Therefore, it is suggested that the thickness of U-rib should be controlled at about $6 \mathrm{~mm}$ in the design, which can effectively prevent the top plate from cracking. In addition, due to the local extrusion between vehicles, the tensile stress appears at the top of the left crossbeam, and the maximum value is about $12 \mathrm{MPa}$. When the thickness of the U-rib is less than $5 \mathrm{~mm}$, the maximum tensile stress at that section decreases with the increase of the thickness of the U-rib, and when the thickness is greater than that of $5 \mathrm{~mm}$, the maximum tensile stress at the section increases with the increase of the thickness. At the top plate of the right beam, the tensile stress in $Z$ direction is very small, and the maximum value is only about $2 \sim 3 \mathrm{MPa}$, and the maximum tensile stress increases gradually with the increase of U-rib thickness, but the change is not obvious.

4.3. Change of Diaphragm Spacing. The longitudinal stress of the top plate can be improved by changing the thickness of U-ribs to increase the longitudinal stiffness. Similarly, it can

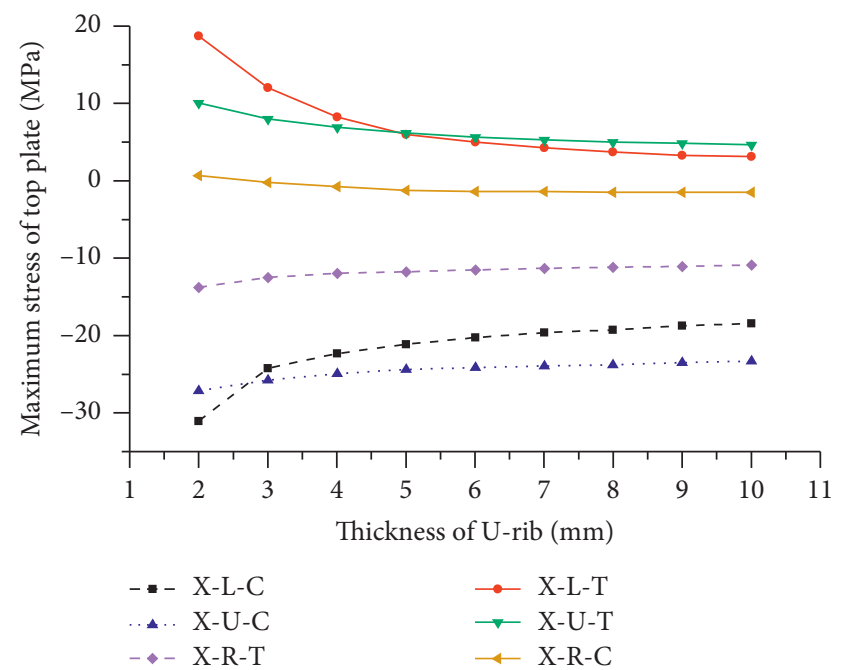

FIgURE 18: Influence of the change of U-rib thickness on the maximum stress in $X$ direction of the top plate.

be achieved by increasing the stiffness of the transverse bridge to reduce the $Z$-direction stress of the top plate. Diaphragm is a member set up between beams to maintain the shape of the section and enhance the transverse stiffness, which mainly plays the role of distributed load. Study shows that reducing the diaphragm spacing is an effective method to increase the transverse stiffness of the bridge.

The calculation results of the model show that except for the stress at the target section in the $X$ direction is mainly compressed, the stresses in other cases are mainly in tension, and this paper only studies the main stress types. Table 4 shows the changes of the maximum stresses in the $X$ and $Z$ directions of the top plate at three sections with the change of diaphragm spacing. It can be seen from Table 4 that when the distance between diaphragms is $9.9 \mathrm{~m}$, the maximum stresses in $X$ and $Z$ directions of each section are large. With the decrease of diaphragm spacing from $9.9 \mathrm{~m}$ to $3.3 \mathrm{~m}$, the maximum stresses in $X$ and $Z$ directions of each section 


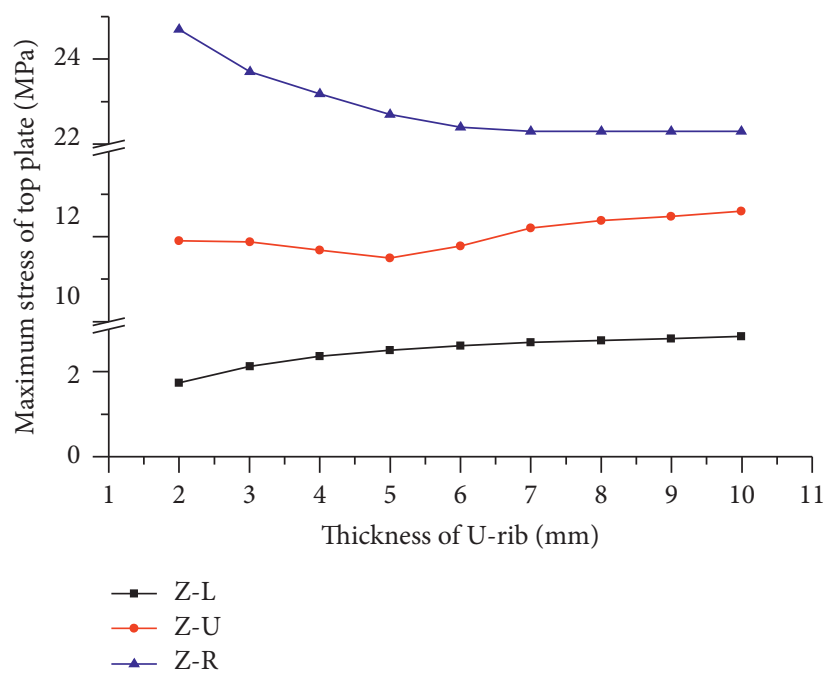

FIgURE 19: Influence of the change of U-rib thickness on the maximum stress in $Z$ direction of the top plate.

TABLE 4: Influence of changing diaphragm spacing on the maximum stress of top plate.

\begin{tabular}{lccccc}
\hline \multirow{2}{*}{ Space of crossbeam $(\mathrm{m})$} & \multicolumn{3}{c}{ X-direction stress $(\mathrm{MPa})$} & \multicolumn{2}{c}{$Z$-direction stress $(\mathrm{MPa})$} \\
& $\mathrm{L}$ & $\mathrm{U}$ & $\mathrm{R}$ & $\mathrm{L}$ & $\mathrm{U}$ \\
\hline 9.9 & 17.3 & -41.5 & 14.5 & 20.8 & 38.1 \\
6.6 & 7.8 & -36.5 & 7.7 & 12.2 & 35.4 \\
3.3 & 5.2 & -23.5 & -1.4 & 12.4 & 18.2 \\
Decrease & $69.9 \%$ & $43.4 \%$ & $109.7 \%$ & $40.4 \%$ & 4.3 \\
\hline
\end{tabular}

decrease obviously. This means that the reduction of the diaphragm spacing increases the longitudinal and transverse stiffness, which would lead to a significant reduction of stress in the $X$ and $Z$ directions. The maximum stresses in the $X$ and $Z$ directions of the top plate at the target section are obviously larger than those at the left and right sections, and the reduction of the distance between beams has the greatest influence on the maximum stress of the top plate at this section. With the decrease of diaphragm spacing from $9.9 \mathrm{~m}$ to $3.3 \mathrm{~m}$, the maximum stress in the $X$ direction decreases from $41.5 \mathrm{MPa}$ to $23.5 \mathrm{MPa}$, reducing by $43.4 \%$. In the $Z$ direction, the maximum stress changed from $38.1 \mathrm{MPa}$ to 22.3 MPa, a decrease of $41.5 \%$. However, no matter how the diaphragm spacing changes, the stresses in the $X$ and $Z$ directions at the wheel section are still the largest. It also can be seen that a change in crossbeam space from $6.6 \mathrm{~m}$ to $3.3 \mathrm{~m}$ causes a smaller stress to drop than a change in crossbeam space from $9.9 \mathrm{~m}$ to $6.6 \mathrm{~m}$. This is because that when the crossbeam space decreases, the self-weight of beam would increase, which could increase the stress on the beam.

4.4. Change of Axle Load of Vehicle. The damage of automobile axle load to highway pavement conforms to the "Four-Time Method"; that is, if the axle load is doubled, the degree of road damage would increase by 16 times. The empty weight of the loaded vehicle used in this loading test is
$20 \mathrm{t}$, and the nuclear load weight is $10 \mathrm{t}$. The change of the top plate stress of three sections during the loading vehicle from empty to overloading was studied by changing the axle load in the model. And in the model calculation, the analysis type was static analysis. Under the vehicle load, the $X$-direction top plate at the target section and the right crossbeam section is mainly under compression, while in other cases, the top plate is mainly under tension, and only the main stress types are extracted as shown in Figure 20. It can be seen that the maximum tensile and compressive stresses increase linearly with the increase of vehicle load. Among them, the maximum stresses in the $X$ and $Z$ directions of the target section are larger than those of the other two sections, and the change of them with the axle load is the most significant. During the change process of axle load from $20 \mathrm{t}$ to $60 \mathrm{t}$, the maximum tensile stress in the $Z$ direction increases by $194.6 \%$ from $14.9 \mathrm{MPa}$ to $43.9 \mathrm{MPa}$, and the maximum compressive stress in the $X$ direction increases by $207.5 \%$ from $15.9 \mathrm{MPa}$ to $48.9 \mathrm{MPa}$. In addition, there is a certain change in the $Z$-direction stress at the top plate of the left crossbeam, from $6.8 \mathrm{MPa}$ to $19.2 \mathrm{MPa}$, an increase of $182.4 \%$, while in other cases, the maximum stress of the top plate is basically unchanged. According to the position of pavement cracks and the calculation result, it can be seen that the pavement cracks were mainly caused by the load of heavy vehicles and had little relation with the shear lag effect because the tensile stress on the top plate at the direct action 


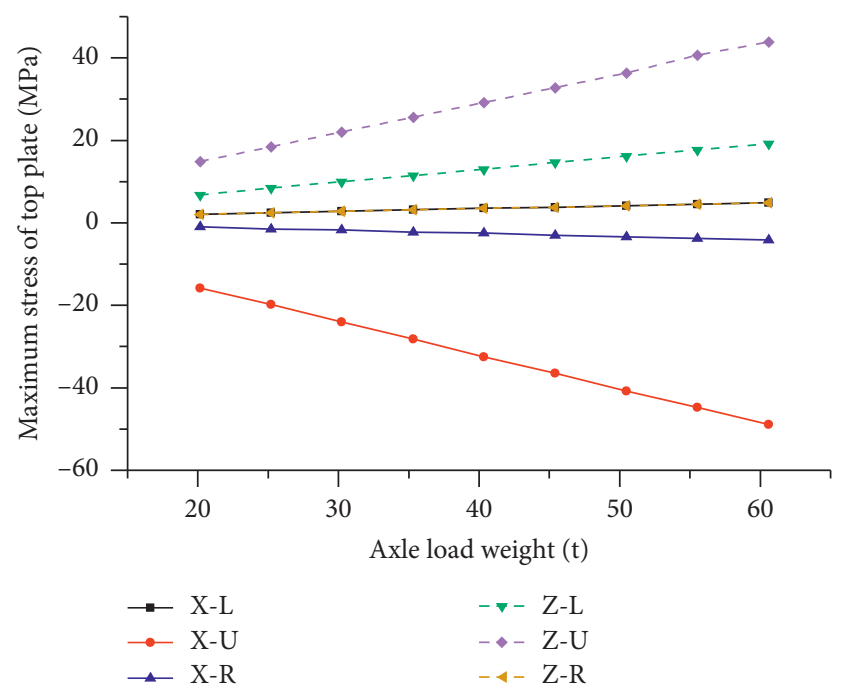

Figure 20: Influence of the change of axle load on the maximum stress of the top plate.

of the wheel would exceed the tensile limit of the pavement. Therefore, the vehicle load should be restricted, and the quality of pavement should be improved.

\section{Conclusions}

In this study, the mechanical performance of a self-anchored suspension bridge with ultra-wide double-sided steel box girder was studied based on the field test, and a parametric study was conducted to investigate the influences of various parameters on the mechanical performance of the girder. Based on the present study, the following conclusions are drawn:

(1) The test results show that the deformation and stress of the Yunlongwan Bridge under vehicle load meet the requirements. The bridge has a good integrity, and the bridge deformation is symmetrical under symmetrical load. While under the eccentric load, the main girder would obviously twist, and the internal force of suspenders on both sides of the bridge are uneven. The top plate would have alternating stress which may cause a risk of fatigue damage.

(2) There is an obvious shear lag effect in the ultra-wide double-sided box girder. Under the influence of shear lag effect, large stresses are generated at the junction of top plate and web. The shear lag coefficient suddenly increases at the middle point of the top plate and the intersection of the top plate and the web. The existence of suspenders and crossbeam would reduce the shear lag coefficient but would not change its variation law.

(3) The changes of U-rib thickness and diaphragm spacing would significantly affect the stiffness of double-sided steel box girder, thus changing the maximum longitudinal stress on the top plate of the main girder. When the U-rib thickness increases from $2 \mathrm{~mm}$ to $4 \mathrm{~mm}$, the peak longitudinal stress reduces obviously and becomes stable when U-rib thickness exceeds $4 \mathrm{~mm}$. In addition, the peak longitudinal stress decreases when the diaphragm spacing reduces from $9.9 \mathrm{~m}$ to $3.3 \mathrm{~m}$.

(4) The maximum stress in the top plate of the girder increases linearly with the increase of vehicle axle load. When the vehicle axle load increases from $20 \mathrm{t}$ to $60 \mathrm{t}$, the maximum tensile and compressive stresses in the top plate at the wheel position change most significantly, increasing to $194.6 \%$ and $207.5 \%$, respectively. It indicates that overloading has a greater hazard to the bridge deck and vehicle overloading should be strictly prohibited.

\section{Data Availability}

The data used to support the findings of this study are available from the corresponding author upon request.

\section{Conflicts of Interest}

The authors declare that there are no conflicts of interest regarding the publication of this paper.

\section{Acknowledgments}

This research was funded by projects of National Natural Science Foundation of China (51408040), Natural Science Foundation of Shaanxi Provincial Department of Education (2017JM5110), Science and Technology Plan Project of Shaanxi Provincial Department of Communications (1715K), and Natural Science Research of Anhui University (KJ2019A1134).

\section{References}

[1] X. Wang, H. Wang, Y. Sun, X. Mao, and S. Tang, "Processindependent construction stage analysis of self-anchored suspension bridges," Automation in Construction, vol. 117, Article ID 103227, 2020.

[2] Y. Liu, C. Yang, and Z. Tan, "Hybrid element-based virtual distortion method for finite element model updating of bridges with wide-box girders," Engineering Structures, vol. 143, pp. 558-570, 2017.

[3] Y.-H. Zhang and L.-X. Lin, "Shear lag analysis of thin-walled box girders based on a new generalized displacement," Engineering Structures, vol. 61, pp. 73-83, 2014.

[4] H. Li, S. Laima, J. Ou et al., "Investigation of vortex-induced vibration of a suspension bridge with two separated steel box girders based on field measurements," Engineering Structures, vol. 33, no. 6, pp. 1894-1907, 2011.

[5] Z. Y. Xia, A. Q. Li, J. H. Li, and M. J. Duan, "FE model updating on an in-service self-anchored suspension bridge with extra-width using hybrid method," Applied Sciences, vol. 7, no. 2, p. 91, 2017.

[6] Z. Sun, D. M. Siringoringo, and Y. Fujino, "Load-carrying capacity evaluation of girder bridge using moving vehicle," Engineering Structures, vol. 229, Article ID 111645, 2021.

[7] H. S. Park, Y. S. Park, J. J. Lee, J. S. Kong, and C. G. Lee, "Evaluation of load carrying capacity of a PC girder bridge using model updating techniques," in Proceedings of the 2011 
International Conference on Multimedia Technology, Hangzhou, China, 2011.

[8] C. Wu, Y. Yuan, and X. Jiang, "Fatigue behavior assessment method of the orthotropic steel deck for a self-anchored suspension railway bridge," Procedia Engineering, vol. 161, pp. 91-96, 2016.

[9] Z. Jin, S. Pei, X. Li, and S. Qiang, "Probabilistic evaluation approach for nonlinear vehicle-bridge dynamic performances," Journal of Sound and Vibration, vol. 339, pp. 143156, 2015.

[10] J. He, Y. Liu, and B. Pei, "Experimental study of the steelconcrete connection in hybrid cable-stayed bridges," Journal of Performance of Constructed Facilities, vol. 28, no. 3, pp. 559-570, 2014.

[11] F. Madrazo-Aguirre, A. M. Ruiz-Teran, and M. Ahmer Wadee, "Dynamic behaviour of steel-concrete composite under-deck cable-stayed bridges under the action of moving loads," Engineering Structures, vol. 103, pp. 260-274, 2015.

[12] H. C. Cheng and G. D. Shen, "Study on vehicle load and bridge response of Anqing bridge based on monitoring data," Modern Transportation Technology, vol. 14, no. 5, pp. 38-41, 2017, in Chinese.

[13] Y. X. Ding, D. C. Zhang, Y. F. Zhang, and Y. C. Xu, “Analysis of bridge displacement response and its correlativity under measured vehicle loads," World Bridges, vol. 46, no. 194, pp. 70-75, 2018, in Chinese.

[14] J. Zhang, H. Peng, and C. S. Cai, "Destructive testing of a decommissioned reinforced concrete bridge," Journal of Bridge Engineering, vol. 18, no. 6, pp. 564-569, 2013.

[15] K. Yokozeki and C. Miki, "Fatigue evaluation for longitudinal-to-transverse rib connection of orthotropic steel deck by using structural hot spot stress," Welding in the World, vol. 60, no. 1, pp. 83-92, 2016.

[16] G. Zhou, A. Li, J. Li et al., "Test and numerical investigations on the spatial mechanics characteristics of extra-wide concrete self-anchored suspension bridge during construction," International Journal of Distributed Sensor Networks, vol. 15, no. 12, 2019.

[17] G.-p. Zhou, A.-q. Li, J.-h. Li, and M.-j. Duan, "Test and numerical investigations on static and dynamic characteristics of extra-wide concrete self-anchored suspension bridge under vehicle loads," Journal of Central South University, vol. 24, no. 10, pp. 2382-2395, 2017.

[18] S. Y. Li, Y. Hong, H. Y. Gou, and Q. H. Pu, “An improved method for analyzing shear-lag in thin-walled girders with rectangular ribs," Journal of Constructional Steel Research, vol. 177, Article ID 106427, 2020.

[19] J. C. Zang, Research on Force Analysis and Key Technologies of Heavy Load Traffic Pavement of Cement Concrete Bridge Traffic, Hebei University of Technology, Tianjin, China, 2014, in Chinese.

[20] P. Lu, Z. Xu, Y. Chen, and Y. Zhou, "Prediction method of bridge static load test results based on Kriging model," Engineering Structures, vol. 214, Article ID 110641, 2020.

[21] MOT JTG/T J21-01-2015, Load Test Method for Highway Bridge, People's Communications Publishing House, Beijing, China, 2016, in Chinese.

[22] JTG D64-2015, Specifications for Design of Highway Steel Bridge, People's Communications Publishing House, Beijing, China, 2015, in Chinese.

[23] X.-W. Sheng, W.-Q. Zheng, Z.-H. Zhu, Y.-P. Qin, and J.-G. Guo, "Full-scale fatigue test of unit-plate ballastless track laid on long-span cable-stayed bridge," Construction and Building Materials, vol. 247, Article ID 118601, 2020.
[24] Y. Chen, J. Dong, T. Xu, Y. Xiao, R. Jiang, and X. Nie, “The shear-lag effect of composite box girder bridges with corrugated steel webs and trusses," Engineering Structures, vol. 181, pp. 617-628, 2019.

[25] L. Zhu, J. Nie, F. Li, and W. Ji, "Simplified analysis method accounting for shear-lag effect of steel-concrete composite decks," Journal of Constructional Steel Research, vol. 115, 2015.

[26] AASHTO LRFD, AASHTO LRFD Bridge Design Specifications, American Association of State Highway and Transportation Officials, Washington, DC, USA, 8th edition, 2017. 